\title{
APPLIED ERGONOMIC METHODOLOGY FOR CURRENT ENGINEERING PRACTICE
}

\begin{abstract}
A human factor is part and parcel of each work system. The current ergonomic methodology enables applications related to the evaluation and design of work systems that take into account both basic aspects of each work system, namely the technical and human aspects. The contribution focuses on the hierarchical classification of methods intended for the use in work systems under the conditions of current engineering practice.
\end{abstract}

\section{Introduction}

Ergonomics, or the study of human factors is defined by a valid international standard as the scientific discipline concerned with the study of interactions among humans and other elements of a system, and the profession that applies theoretical knowledge, principles, empirical data and methods to design orientated towards the optimization of human well-being and overall system performance [7]. Ergonomic terminology is considerably complicated by interpretation and uncertainties in the name of the discipline itself. The problem consists especially in the synonymic use of terms "ergonomics" and "human actor" or "human factor". Both these terms are worldwide adopted terms for the theory and practice of learning of human characteristics and abilities, and then using of acquired knowledge for improving interactions among people and things used by them and environments in which they do so [1].

In ergonomics, the design process, management system, methods, equipment and environment are always evaluated in relation to human abilities, capacity and human limit values. It is typical of a modern world that disciplines of present-day relevance and value are generally multi-, inter- and trans-disciplinary, and thus they cannot be defined simply [2].

A considerable number of methods so far published, i.e. more than three hundred methods, including obligatory and recommended methods, are greatly indebted to special methodological division, and do not give technicians - engineers, who carry out the optimization of work systems, a sufficient overview of possibilities of applications of ergonomic evaluation methods. With reference to the great number of methods and variety in possibilities of their application, the need appears to summarise and classify systematically the methods, above all with regard to transparency, effectiveness and significance of required applications. Under the current conditions of engineering practice, the points of view of obliga- tion and also economical, professional and time demands play a great role.

The significance of ergonomics increases with the efficiency of applications and on the basis of correctly used methods of design and evaluation of effectiveness of ergonomic solutions. The ergonomic methodology deals with principles, procedures, methods and techniques that are at present used or can be used in analyses, designs and evaluations of machinery in relation to machineryhuman interaction, analyses, designs and evaluations of work positions, work tasks, working conditions, work environment and work organisation. Requirements of modern developing companies for increasing work performance, quality and productivity and a related increase in competitiveness and better market positions are reasons for increasing the significance of correct ergonomic design and functionality of work systems.

\section{Methodological Principles of Ergonomic Activities in Work Systems}

For managing successfully the process of a comprehensive ergonomic evaluation and for achieving the improvement or optimization of a work system, a system approach to solving is expected. The system approach shall be applied in cases of making ergonomic analyses for current as well as new situations. In evaluations and designs basic ergonomic principles shall be always utilized for the design of optimal working conditions with regard to well-being, safety and health of workers, including the development of existing skills and the acquirement of new skills, with taking technological and economic effectiveness and efficiency into account [4].

Accepted and valid international standards are orientated towards the evaluation and design of work systems and can be

\footnotetext{
* Svetla Fiserova

Department of Safety Management, Faculty of Safety Engineering, VSB - Technical University of Ostrava, Ostrava - Vyskovice, Czech Republic,

E-mail: svetla.fiserova@vsb.cz
} 
used for other areas of human activity as well. In the process of ergonomic evaluation and design, the major interactions between or more people and the components of the work system, such as tasks, equipment, workspace and environment shall be dealt with. The process of ergonomic design of a work system can be divided into the following phases:

1. formulation of goals (analysis of requirements),

2. analysis and allocation of functions,

3. design concept,

4. detailed design,

5. realization, implementation and validation,

6. evaluation.

All the phases contain a fixed methodological framework, e.g. in the form of the detailed design it is necessary to evaluate and design individual elements of the parts of which the work system is composed. In accordance with the relevant international standard, the detailed design should be carried out so that all related ergonomic knowledge and requirements may be respected. The work system design shall include the design of the following components:

1. work organisation

2. work tasks

3. work

4. work environment

5. work equipment, hardware and software

6. workspace and workstations.

For the evaluation of quality of the design of technical components of a work system, the concept of usability provides a suit- able framework, because usability covers all three categories of evaluative criteria.

Methods of evaluation in relation to

Table 1 evaluative criteria [3]

\begin{tabular}{|l|l|}
\hline Category (aspect) & Evaluation methods \\
\hline Health and well-being & $\begin{array}{l}\text { medical, physiological, objective, subjective, } \\
\text { psychological }\end{array}$ \\
\hline Safety & $\begin{array}{l}\text { reliability, errors, hazardous behaviour, near } \\
\text { misses, accidents }\end{array}$ \\
\hline Performance & quality, quantity
\end{tabular}

The ergonomic approach to the design scheme for work system optimization can be characterized by the following parameters:

a) active participation of users and clear understanding of user requirements and the given task;

b) suitable allocation of functions to users and technical resources;

c) iterative design schemes;

d) multidisciplinary design.

Ergonomic design activities are interrelated.

Ergonomically designed work systems increase safety, effectiveness and performance, improve human working and living conditions and compensate unfavourable effects on human health and performance. A good ergonomic design has thus favourable effects on a work system and human reliability in the system. The work system is based on a conception connecting operators, work equipment (including machines), workspace, work environment, work

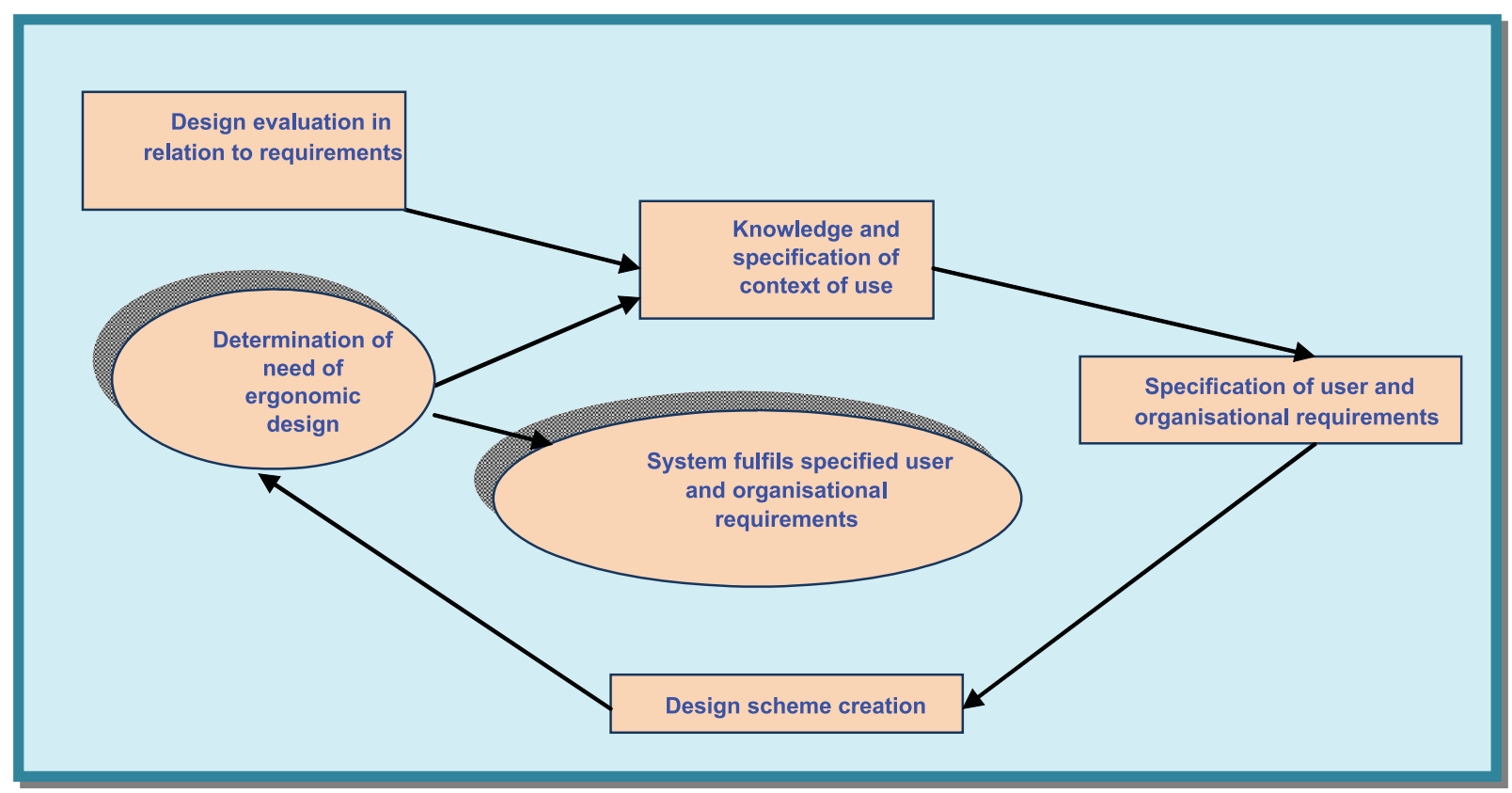

Fig. 1 Interrelations between ergonomic design activities [3] 
process, work task, management and organisation and also their interrelations into one unit.

The design shall take into account the following:

1. anthropometry and biomechanics

2. mental abilities

3. displays, indicators and control actuators

4. interaction with the physical work environment

5. interaction in the work process.

Interactions among the design of machinery, design of work task and job position are of key importance to the accomplishment of goals of ergonomic activities. Work systems require high productivity and high quality and also health and safety provision [6]. The best work systems are based on the utilization of experienced employees in such job positions that are designed well and that consist of suitably designed work tasks.

\section{Methods Used in Ergonomic Activities in Work Systems}

Requirements for the comprehensiveness of outputs of ergonomic activities are high, and thus there is a need to systematise and structure input data on methods for these purposes so that results of ergonomic designs may be effective and may lead to work system optimization. Primarily for all ergonomic disciplines it is true that the results of evaluation are intended for the generalisation and prediction of human factor position above all from the point of view of performance, quality, safety, reliability, and for the reduction of undesirable health effects of work on humans. Subsequently, the methods also play a really critical role in the validation of obtained generalisations and predictions. Of the determination of criteria for ergonomic evaluation and the correct selection of methods, intentions and goals of applications especially in the course of the following items are decisive:

- collection of data on work systems, technologies and humans,

- system development and improvement,

- evaluation of system layouts,

- evaluation of impacts and effects of work on humans,

- cognition of why systems fail,

- development of management programmes based on the ergonomic approach.

A considerable number of modern methods of ergonomic evaluation and design are usually divided by authors according to various methodological and ergonomically logical criteria. In spite of the fact that to the processes of ergonomic evaluation, improvisational characteristics of procedures are significant, namely according to the quantity of aspects, factors, influences and interfaces in systems, to each ergonomic investigation its framework structure is of importance.

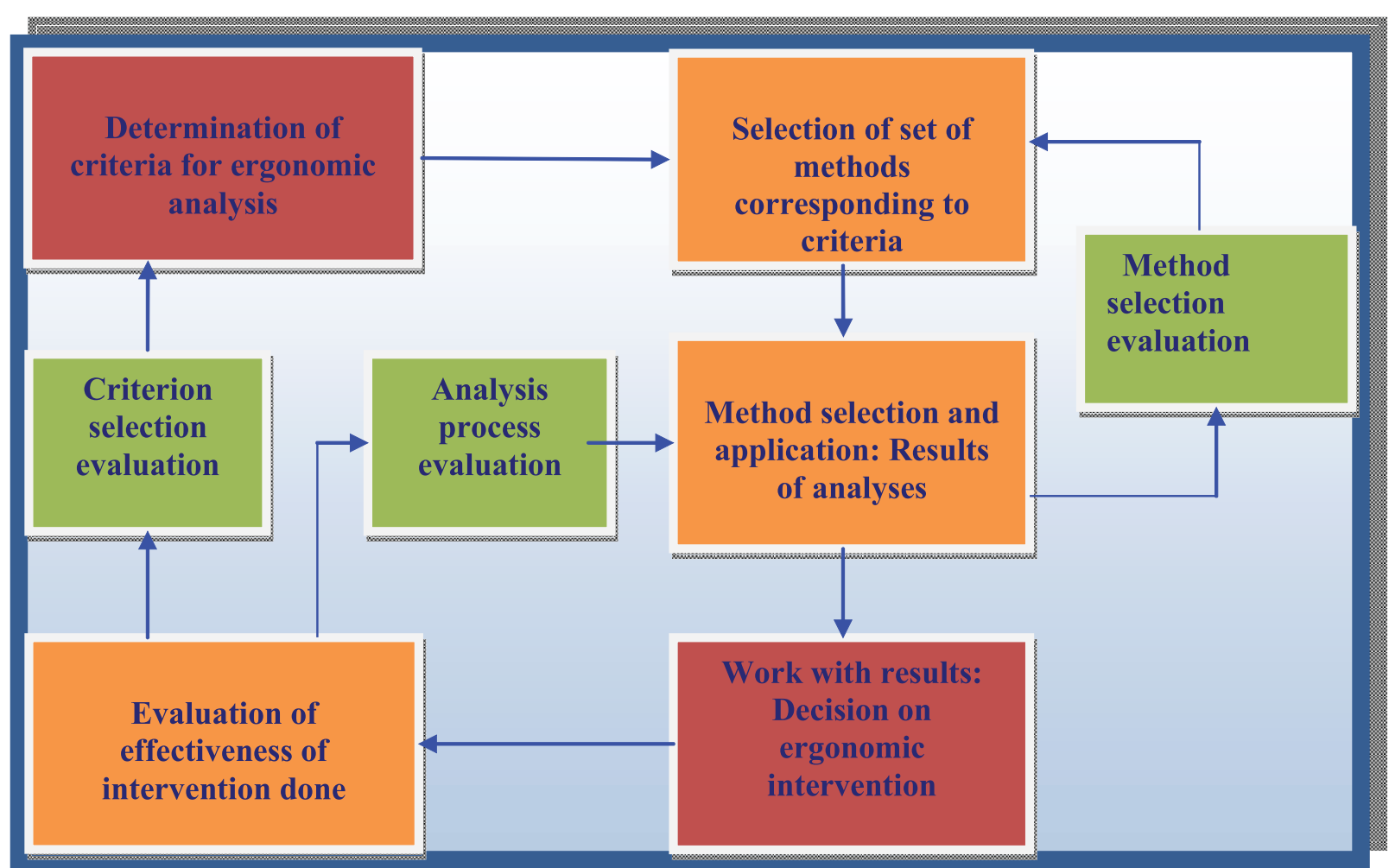

Fig. 2 Process of evaluation, method selection and ergonomic intervention [5] 
The basis of the framework structure of each evaluation is the formulation of goals of investigation, study, research. What is of importance to making decisions about methods, techniques and recognition procedures is the cognition of situation under concrete conditions.

Steps leading to a successful ergonomic activity shall be, with regard to a broad basis and multidisciplinary character, systematised in accordance with the principles of ergonomic designs.

\section{Classification of Ergonomic Methods according to the Hierarchy of Obligation}

The great number of current methods of the ergonomic evaluation and design of work systems determines the need to systematise them so that they may be lucid and usable under the presentday modern conditions of engineering practice with high requirements for effectiveness and economic return of activities carried out.

After application of rules and principles of ergonomic evaluation and design and correct determination of priorities of ergonomic applications in work systems, subsequent dealing with the ergonomic approach is to be subject, also with reference to the availability of methods used in ergonomic activities for engineering practice, to a uniform hierarchy.

A proposal for the division of methods used in ergonomic activities for their application in engineering practice assumes and respects the hierarchy of obligation.

1. Methods obligatory and methods necessary for the application of obligatory requirements (i.e. minimum requirements for occupational safety and health)

2. Methods recommended, developing obligatory requirements and contained in international standards related to the ergonomics of work systems

3. Methods supplementary, identifying and analysing specific areas of human activities in work systems

\subsection{Methods obligatory and methods necessary for the application of obligatory requirements (i.e. minimum requirements for occupational safety and health)}

Methods used for health risk assessment are to be taken as the basis of all ergonomic activities in work systems. Applications of these methods that are obligatory in the range of valid legal regulations are intended especially for use in a real environment. The use of them is connected with a concrete work process with concrete work activities and tasks carried out in the framework of a characteristic working shift. Exposure assessment has become more or less an independent specialisation with its own international professional society ISEA (International Society of Expo- sure Assessment). The analysis of health risk factors at work is based on the systematic monitoring of all factors of work environment and working conditions from the point of view of human health load due to these factors and their possible harmful effects on occupational health and safety. It predicts a possibility of occurrence of occupational injuries, occupational diseases or other injuries to health associated with work and working conditions (e.g. diseases connected with work). Part of this activity is the evaluation of proposals for measures to limit or eliminate risks, including the check and evaluation of accepted measures. The assessment of all health risks, with some exceptions, rests on requirements for objectivity, which brings with it the fact that for the reproducibility and subsequent classification of results of evaluation it is necessary to accept the response of the "average healthy human" organism.

\subsection{Methods recommended, developing obligatory requirements and contained in international standards related to the ergonomics of work systems}

The detailed evaluation of working conditions with a view to their optimization can be made according to valid international standards so that ergonomic activities may be in accordance with generally valid rules and principles of ergonomic design. Methods contained in international standards are recommended and take into account also criteria not dealt with by obligatory regulations. It is a case of analysis procedures with respecting differences e.g. anthropometric and biomechanical, in age, etc. Work systems designed to respect also requirements and recommendations of international standards increase safety, effectiveness and efficiency, improve human working and living conditions and diminish unfavourable effects on human health and work performed. For this reason, a good ergonomic design has a favourable influence on a work system and human reliability in this system.

The recommended methods that develop obligatory requirements and are contained in international standards are in the draft classification for applications in engineering practice divided into methods intended for the assessment of:

- Machinery risks

- Human physical performance

- Human mental performance

- Human performance with regard to physical, chemical and physiological working conditions

- Human sensory performance

- Ergonomic design of control centres

- Display units and clerical work

\subsection{Methods supplementary, identifying and analysing specific areas of human activities in work systems}

The set goal in the area of optimization of work with regard to health protection, safety and reliability and also optimization of work efficiency, work quality and productivity can be achieved by applications of other suitable and selected methods that are contained neither in any regulations nor international/national stan- 
dards. Their application follows from the requirements given by abilities, limits and requirements of all elements of a system [6]. Supplementary methods can be applied in any phase of ergonomic design; they do not replace either obligatory or recommended methods and can be divided into the following eleven categories:

\section{Data Collection Methods}

Data collection methods are used for the collection of specific data related to the system and scenarios. They are basic methods for designing and planning new systems and for evaluating currently operated systems.

\section{Task Analysis Methods}

These methods are used for analyses of human position and human role in executing tasks and scenarios in systems. Analytical methods specify tasks and scenarios (e.g. working procedures, task contents) to individual steps, for human-machine, human-human (other persons) interactions.

3. Cognitive Task Analysis (CTA) Methods

CTA methods are used for the description of yet not known sets of arrangement of activities and operations. They are used in the description of mental processes of system operators in the course of completing and making up operations to be performed and their sets.

4. Process Charting Methods

They are used for the graphic representation of tasks and processes by means of standardized symbols. The output of process charting methods and techniques can be a basis for the cognition and understanding of different sequences of tasks that are contained as part in the overall scenario - a detailed overview of work activities. Furthermore, they are used for the clarification of time schedules of operations that may occur and for the clarification of which technological aspects of the system and its relations are required.

\section{Human Errors Identification (HEI) Method}

Human error identification methods are designed for the prediction, identification of possible human errors in a work system, especially those that may occur in interaction with machinery. By the application of Human Reliability Analysis (HRA) methods is then carried out the quantification of cases of human failure in the system.

\section{Mental Workload Assessment Methods}

A mental workload represents a level of abilities of a human to satisfy requirements imposed on the human. Quite a lot of such methods exist and they can be used widely in the assessment of processes and also in the design of them.

\section{Situation Awareness Assessment Methods}

Situation awareness assessment methods are used for the analysis of human preparedness for situations that may occur in a system. They are used for the determination of requirements for knowledge and abilities of operators and machinery operators and are also a confrontation with the determination of target requirements for system functionality and quality of management preparedness in relation to the corresponding comprehension of formulation of individual operations and their interrelations. They are also used for planning the overall layout of the system. These techniques are used for partial as well as comprehensive evaluations of mainly dynamic systems.

\section{Interface Analysis Methods}

Methods and techniques used for the analyses of interfaces in a system serve the evaluation and design and planning of requirements and functions of interconnections between specific elements of a system with a view to optimization, including the evaluation of e.g. employee satisfaction and consideration of employee opinion.

\section{Design Methods}

They are the methods that are typically used in designing and planning new systems, activities and human factor relations in processes - of individuals, groups and sequences in the framework of large working teams.

\section{Performance Time Prediction Methods}

They are used for the determination of corresponding time requirements for work operations, tasks and activities, including the creation of designs of overall detailed overviews of work activities and scenarios.

11. Team Assessment Methods

They are used for the assessment of performance of groups and teams for individual activities and also overall scenarios and work images. For such assessments, a whole series of aspects is usually specified and those are later evaluated and compared. Requirements and the level of intercommunication, awareness, co-decision-making, load and co-operation are assessed.

\section{Conclusion}

In the framework of ergonomic evaluations of work systems, equal attention shall be paid to three basic aspects from the point of view of human position in a work system. They are the propositional aspect, task aspect and social aspect, and their interfaces. For these purposes, assuming the hierarchical process, the applications of methods intended for data collection, analytical methods and presentation methods are necessary. New technologies together with development lead on the one hand to the facilitation of some working procedures; on the other hand they bring growing requirements for the professional and also psychical abilities of employees to give expected and high-quality work performance. [8] Engineering practice usually inclines towards extensive and detailed investigations of working conditions and subsequent ergonomic interventions provided that sufficient arguments on benefits and improvements are available. Respecting the modern ergonomic principles, including the systematic classification and hierarchical analysis of selected methods can contribute to the wide use of specific ergonomic designs, which have been implemented so far only in a limited degree, in practice. Only a correctly and reliably made ergonomic evaluation, utilizing the combination of methods that are suitable and verified tools, can lead to an effective and longterm ergonomic solution in the framework of work systems.

\section{Acknowledgement}

This contribution was written in the framework of the iNTegrisk FP7 project No.213345 "Early Recognition, Monitoring and Integrated Management of Emerging, New Technology Related Risks". 


\section{References}

[1] WILSON, J.R., CORLETT, N.: Evaluation of Human Work, Taylor\&Francis Group, CRC, 2005, ISBN: 0-415-26757-9

[2] CHARLTON, S., O'BRIEN, T.: Handbook of Human Factors Testing and Evaluation, 2001, LEA, ISBN: 0805832904

[3] KARWOWSKI, W.: Handbook of Standards and Guidelines in Ergonomics and Human Factors, IEA, UK, 2006, ISBN: 0-8058-4129-6

[4] SALVENDY, G.: Handbook of Human Factors and Ergonomics, John Wiley \& Sons, Inc., USA, 2006, ISBN: 0-471-44917-2

[5] STANTON et al.: Handbook of Human Factors and Ergonomics Methods, CRC Press, 2005, ISBN: 0-415-28700-6

[6] TAYLOR et al: Enhancing Occupational Safety and Health, Elsevier, UK, 2004, ISBN: 0-7506-6197-6

[7] KARWOWSKI, W., MARRAS, W.S.: Occupational Ergonomics, CRC Press LLC, 2003, ISBN: 0-8493-1802-5

[8] LOVECEK, T: Present and Future Ways of Physical Property Protection, Communications - Scientific Letters of the University of Zilina, No. 1/2008, ISSN 1335-4205. 